\title{
Article
}

\section{Machiavellianism and romantic relationship dissolution}

Brewer, Gayle and Abell, Loren

Available at http://clok.uclan.ac.uk/16399/

Brewer, Gayle ORCID: 0000-0003-0690-4548 and Abell, Loren (2017)

Machiavellianism and romantic relationship dissolution. Personality and Individual Differences, 106 . pp. 226-230. ISSN 0191-8869

It is advisable to refer to the publisher's version if you intend to cite from the work. http://dx.doi.org/10.1016/j.paid.2016.11.001

For more information about UCLan's research in this area go to http://www.uclan.ac.uk/researchgroups/ and search for < name of research Group>.

For information about Research generally at UCLan please go to http://www.uclan.ac.uk/research/

All outputs in CLoK are protected by Intellectual Property Rights law, including Copyright law. Copyright, IPR and Moral Rights for the works on this site are retained by the individual authors and/or other copyright owners. Terms and conditions for use of this material are defined in the policies page.

\section{CLoK}

Central Lancashire online Knowledge www.clok.uclan.ac.uk 


\section{Machiavellianism and Romantic Relationship Dissolution}

Despite the frequency with which relationships are dissolved and the consequences of this dissolution, few studies have considered the manner in which individual differences (rather than characteristics of the relationship itself) influence the selection of a break up strategy or break up related distress. The current studies were conducted to address this issue. In Study 1, women $(N=141)$ completed Machiavellianism (Christie \& Geis, 1970) and break up strategy (Collins \& Gillath, 2012) questionnaires. Women with high levels of Machiavellianism were more likely than those with low levels of Machiavellianism to employ Avoidance / Withdrawal, Cost Escalation, Manipulation, and Distant / Mediated Communication when terminating a relationship. In Study 2, women $(N=125)$ completed Machiavellianism (Christie \& Geis, 1970) and break up distress (Field, Diego, Pelaez, Deeds, \& Delgado, 2010) measures. Machiavellianism did not predict post relationship distress. Findings are discussed in relation to the Machiavellian interpersonal style and relationship preferences.

Keywords: break up; distress; Machiavellianism; relationship dissolution; romantic relationships

\subsection{Introduction}

Romantic relationships form an important part of our social landscape. In most Western societies, men and women follow a pattern of serial monogamy characterised by the repeated formation and dissolution of romantic relationships (Fisher, 1985; MacDonal, 1995). When relationships are terminated (i.e., a 'break up'), it is typically instigated by one member of the couple, with mutual agreement less prevalent (Hill, Rubin, \& Peplau, 1976). Factors increasing the likelihood of relationship dissolution include a partner's failure to meet 
expectations (e.g., sexual dissatisfaction), unequal commitment, a desire for freedom, and external factors (Connolly \& McIsaac, 2009; Hill, Rubin, \& Peplau, 1976; Sprecher, 1994). Though these events are relatively common (Knox, Zusman, \& Nieves, 1998; Robak \& Weitzman, 1998), romantic relationship dissolution is associated with substantial distress and a range of emotions including anger, confusion, sadness, and regret are reported (Perilloux \& Buss, 2008; Sbarra, 2006). The termination of a relationship also has important consequences for physical and mental health (Davis, Shaver, \& Vernon, 2003; Kiecolt-Glaser et al. 1987; Monroe, Rohde, Seeley, \& Lewinsohn, 1999). Lower levels of distress are experienced by those initiating the break up (Attridge, Berscheid, \& Simpson, 1995; Drigotas, 1996; Sprecher, Felmlee, Metts, Fehr \& Vanni, 1998); however, those who make the decision to break up also report a range of negative outcomes such as sleep irregularities and headaches (Akert, 1998).

Previous research has typically focused on the consequences of relationship dissolution and those factors influencing the impact of a relationship break up rather than the manner in which the break up occurs. A range of strategies may be employed to end a relationship (Baxter, 1982, 1984), which vary according the level of compassion displayed towards the partner and the level of directness (Baxter, 1985; Sprecher, Zimmerman, \& Abrahams, 2010). Collins and Gillath (2012) identify seven break up strategies: avoidance / withdrawal (e.g. avoiding contact with the partner); positive tone / self-blame (e.g. taking the blame for the break up); open confrontation (e.g. providing honest explanations for the break up); cost escalation (e.g. making the relationship increasingly unpleasant); manipulation (e.g. hinting to other people that they wish for a break up), distant / mediated communication (e.g. terminating the relationship indirectly); and de-escalation (e.g. suggesting that the break up is temporary). A range of factors may influence the selection of a break up strategy such as the nature of the relationship (Banks, Altendorf, Greene, \& Cody, 1987; Collins \& Gillath, 2012) 
which subsequently impact the partner's reaction (Lambert \& Hughes, 2010). Despite the frequency with which relationships are dissolved and the consequences of this dissolution, few studies have considered the manner in which individual differences (rather than characteristics of the relationship itself) influence the selection of a break up strategy or break up related distress. This may reflect reports that individual differences (such as the Big Five personality traits) have limited influence on relationship dissolution when compared to relationship factors e.g., commitment, love, and relationship satisfaction (Le, Dove, Agnew, Korn, \& Mutso, 2010). Furthermore, where the impact of individual differences on break up experience has been investigated, this typically focuses on whether relationship dissolution has occurred rather than the strategies employed to break up with a partner or the consequences of this (e.g., Kurdek, 1993; Olderbak \& Figueredo, 2010).

The present studies consider the extent to which Machiavellianism influences the selection of a break up strategy and post break up distress. Machiavellianism, characterised by emotional detachment, distrust, and a willingness to exploit others (Christie \& Geis, 1970; Vecchio \& Sussman, 1991), has been shown to influence the attraction of a romantic partner, relationship quality, and relationship maintenance. For example, those with high levels of Machiavellianism display low levels of relationship commitment, increased infidelity, and higher levels of sexual deception (Ali, \& Chamorro-Premuzic, 2010; Brewer \& Abell, 2015). Previous research also demonstrates that individuals higher in Machiavellianism display concern over their reputation through strategic thinking and do not engage in impulsive behaviour (Christie \& Geis, 1970; Jones \& Paulhus, 2011a; Jones \& Paulhus 2011b).

Indeed although Machiavellianism is associated with hostility, Machiavellian tactics are not (Jones \& Neria, 2015). Such characteristics may influence the strategies that partners employ to end a relationship with a romantic partner. For example, women high on Machiavellianism may adopt strategies that minimise conflict. Indeed whilst in a romantic 
relationship, women with higher Machiavellianism scores use subtle tactics such as covert resistance (e.g., being 'sneaky' when flirting with other men) to resist their partners mate guarding behaviours (Abell \& Brewer, 2016). Such behaviour may be employed to protect their reputation but also allow extra-pair relationships. The use of such subtle tactics are predicted to extend to relationship dissolution. Specifically, women with higher Machiavellianism are predicted to employ subtle strategies to end their romantic relationship that serve to reduce conflict and protect their reputation. These strategies may also retain opportunities for exploitation and manipulation of their former partner, of particular importance given the number of women who retain contact with ex partners either as a friend or lover (Halpern-Meekin, Manning, Giordano, \& Longmore, 2012; Mogilski \& Welling, 2016).

Furthermore, Machiavellianism is associated with a lack of connection to their own feelings (Christie \& Geis, 1970; Wastell \& Booth, 2003) and with seeking closeness in others primarily to manipulate whilst hiding their own vulnerabilities and weakness to order to avoid exploitation themselves (Ináncsi, Láng, \& Bereczkei, 2015; Sherry, Hewitt, Besser, Flett, \& Klein, 2006). Women high on Machiavellianism report that non-romantic relationships provide low levels of intimacy and emotional security (Abell, Brewer, Qualter, $\&$ Austin, 2016) and show a preference for relationships with low levels of emotional closeness and commitment (Ali, \& Chamorro-Premuzic, 2010). This lack of attachment to others and concern for hiding their own vulnerabilities may predict low levels of post break up distress amongst women higher in Machiavellianism.

The current studies investigate the influence of Machiavellianism on the manner in which women break up with their partner and the distress experienced when their partner terminates a relationship. Based on previous research, we predicted that those with high levels of Machiavellianism would be more likely to employ break up strategies involving 
manipulation, avoidance / withdrawal, distant / mediated communication, de-escalation, and cost-escalation, and would be less likely to adopt open confrontation. No prediction was made for positive tone / self-blame as it was unclear whether those high on Machiavellianism would be less concerned with the feelings of their partner (and hence be less likely to employ this strategy) or more aware of the potential for retaliation (and hence be more likely to employ this strategy). Due to the poor relationship quality experienced by those high on Machiavellianism, we predicted lower post break up distress for those with high levels of Machiavellianism. Important sex differences occur with regard to relationship dissolution; for example women are more likely than men to initiate a break up (Hill, Rubin, \& Peplau, 1976), cite different reasons for break ups (Lampard, 2014), and adjust better to relationship dissolution (Evans, Scourfield, \& Moore, 2014; Helgeson, 1994). Furthermore, it has been argued that the influence of Machiavellianism on interpersonal relationships may differ for men and women (McHoskey, 2001). Hence, we investigated the influence of Machiavellianism on relationship break up behaviour in women only.

\subsection{Study 1: Method}

\subsection{Participants}

Heterosexual women $(N=141)$ aged $16-70$ years $(M=22.96, S D=8.15)$ were recruited via online research forums and social networking sites. Average relationship length and length of time between break up and study completion were $27.90(S D=41.46)$ and $22.33(S D=35.50)$ months respectively.

\subsection{Materials and Procedure}

Each participant completed the Mach IV (Christie \& Geis, 1970) and the Break up Strategies Questionnaire (Collins \& Gillath, 2012) in relation to the romantic partner that they most recently decided to break up with. 
The Mach IV (Christie \& Geis, 1970) is a uni-dimensional measure of

Machiavellianism which assesses interactions with others, morality, and cynicism. The scale contains 20 items rated on a 7 point likert scale $(1=$ strongly disagree to $7=$ strongly agree $)$. Example items include "Never tell anyone the real reason you did something unless it is useful to do so" and "Anyone who completely trusts anyone else is asking for trouble". Ten items were reverse coded and higher scores indicate higher Machiavellianism.

The Break up Strategies Questionnaire (Collins \& Gillath, 2012) is a 43 item measure of the strategies employed to break up with a partner. Participants respond to each item on a 7 point likert scale $(1=$ did not use strategy at all to $7=$ definitely $u$ sed this strategy). These assess 7 strategies: avoidance / withdrawal (11 items); positive tone / selfblame (10 items); open confrontation (4 items); cost escalation (4 items); manipulation (5 items); distant / mediated communication (4 items); and de-escalation (5 items). Example items include "I avoided contact with my partner as much as possible" (avoidance / withdrawal), "I honestly conveyed my wishes to my partner" (open confrontation), and "I intentionally "leaked" my desire to break up to someone I anticipated would inform my partner" (manipulation). One item was reverse coded and higher scores indicate greater use of the break up strategy.

In the present study each measure (Machiavellianism: $\alpha=.70$; avoidance / withdrawal $\alpha=.89$; positive tone / self-blame $\alpha=.84$; open confrontation $\alpha=.71$; cost escalation $\alpha=.80$; manipulation $\alpha=.78$; distant $/$ mediated communication $\alpha=.67$; and deescalation $\alpha=.67$ ) demonstrated acceptable reliability.

\subsection{Study 1: Results}

Significant positive correlations were identified between Machiavellianism and the use of avoidance / withdrawal, cost escalation, manipulation, and distant / mediated communication break up strategies. These data are shown in Table 1. A series of regression 
analyses revealed that Machiavellianism predicted the use of avoidance / withdrawal, $F$ $(1,124)=5.07, p=.026$, cost escalation, $F(1,122)=14.31, p<.001$, manipulation, $F(1,123)$ $=8.40, p=.004$, and distant $/$ mediated communication, $F(1,123)=6.10, p=.015$, such that women with higher levels of Machiavellianism were more likely to employ each break up strategy. Machiavellianism did not predict positive tone / self-blame, $F(1,125)=.56, p=$ .458 , open confrontation, $F(1,125)=.51, p=.476$, and de-escalation, $F(1,122)=1.46, p=$ .230 .

\subsection{Study 1: Discussion}

Study 1 revealed that women higher on Machiavellianism were more likely to adopt manipulative break up strategies e.g., "I promoted new relationships for my partner to make the break up easier". This reflects the manipulative interpersonal style which characterizes Machiavellianism (Christie \& Geis, 1970). Furthermore, women with higher levels of Machiavellianism were more likely to engage in avoidance / withdrawal e.g., "I avoided scheduling future meetings with my partner whenever possible", distant / mediated communication e.g., "I terminated the relationship indirectly (through email, text messaging, or other unidirectional methods of communication)", and cost-escalation e.g., "I became unpleasant to my partner in the hopes that he would make the first move". Together these findings indicate that Machiavellianism is associated with a more deceitful nonconfrontational approach to relationship dissolution and perhaps to relationships on a wider scale. Indeed, Brewer and Abell (2015) demonstrate that Machiavellianism predicts the use of sexual deception (including avoidance of confrontation) within committed romantic relationships. It is perhaps surprising then that women high on Machiavellianism were not less likely to engage in open-confrontation e.g., "I openly expressed to my partner my desire to break up". In part, this inconsistency may reflect the relative success or failure of each strategy. For example, women may first implement the more indirect break up strategies but 
if unsuccessful may resort to open confrontation. Additional research investigating these relationship dynamics from a longitudinal perspective would be beneficial.

\subsection{Study 2: Method}

\subsection{Participants}

Heterosexual women $(N=125)$ aged $16-72$ yrs $(M=24.96, S D=8.97)$ were recruited via online research forums and social networking sites. Average relationship length and length of time between break up and study completion were $22.19(S D=21.08)$ and $23.16(S D=44.22)$ months respectively.

\subsection{Materials and Procedure}

Each participant completed the Mach IV (Christie \& Geis, 1970) and the Break up Distress Scale (Field, Diego, Pelaez, Deeds, \& Delgado, 2010) in relation to the romantic partner that most recently ended a romantic relationship.

As previously described, the Mach IV (Christie \& Geis, 1970) is 20 item measure of Machiavellianism, rated on a 7 point likert scale $(1=$ strongly disagree to $7=$ strongly agree). Example items include "It is safest to assume that all people have a vicious streak and it will come out when they are given a chance" and "It is hard to get ahead without cutting corners here and there".

The Break up Distress Scale (Field, Diego, Pelaez, Deeds, \& Delgado, 2010) contains 16 items adapted from the Inventory of Complicated Grief (Prigerson, Maciejewski, Reynolds, Bierhals, Newsom, \& Fasiczka, 1995). Items are rated on a 7 point likert scale $(1=$ not at all to $7=$ very much so). Example items include "I think about this person so much that it's hard for me to do things I normally do" and "I feel I cannot accept the break up I've experienced". Higher scores indicate greater distress. In the present study each measure (Machiavellianism: $\alpha=.64$; Break up Distress: $\alpha=.95$ ) demonstrated acceptable reliability.

\subsection{Study 2: Results}


Machiavellianism was not significantly correlated with break up distress $(r=.03, p=$ .754). Regression analysis revealed that Machiavellianism did not predict self-reported distress following a romantic relationship break up, $F(1,111)=.10, p=.754^{1}$.

\subsection{Study 2: Discussion}

Study 2 indicates that Machiavellianism does not predict post break up distress. Findings may reflect the complex nature of Machiavellianism and the manner in which Machiavellianism influences romantic relationships. For example, those high on Machiavellianism display low levels of emotional closeness and relationship commitment which are each related to greater post break up distress (Fine \& Sacher, 1997; Simpson, 1987; Sprecher, Felmlee, Metts, Fehr, \& Vanni, 1998). Furthermore, Machiavellianism is associated with increased attractiveness to potential partners and subsequent sexual opportunities (McHoskey, 2001). Together, these findings suggests that those with high levels of Machiavellianism may be less distressed by the loss of a relationship (i.e., break up) and more likely than those with low levels of Machiavellianism to attract a replacement partner. However, relationships may provide those high on Machiavellianism with opportunities for exploitation and manipulation. Hence, the loss of these opportunities may be upsetting. Furthermore, those with high levels of Machiavellianism display distrust and a lack

of faith in others and are more sensitive to rejection by others (Birkás, Láng, Martin, \& Kálla, 2016), which may increase post break up distress. Consequently, a more nuanced measure of break up distress (which ascertains those elements of the break up which are most upsetting) may be required.

\subsection{Discussion}

Findings indicate that Machiavellianism influences the manner in which women break up with their partner but not their distress in relation to a break up. Those with higher levels of Machiavellianism were more likely to display avoidance / withdrawal, cost escalation, and 
employ distant / mediated communication (e.g., email, social networking sites) to terminate a relationship. The use of these strategies indicate a reluctance to engage in more direct break up behaviours that may be uncomfortable due to the emotional resources required. Machiavellianism is associated with being unconnected to one's own and others feelings (Wastell \& Booth, 2003) and thus a direct strategy may highlight these social deficits and expose these women's vulnerabilities.

Furthermore, women with high levels of Machiavellianism report social relationships in which they are the target of emotional manipulation (Abell, Brewer, Qualter, \& Austin, 2016); they may therefore be wary of future retaliation. Of course many people maintain friendships with previous partners (Mogilski \& Welling, 2016) or experience relationship churning i.e., sexual activity with a former partner or an on / off cycle of break-up and reconciliation (Halpern-Meekin, et al. 2012). These provide opportunities for further exploitation; therefore the use of indirect strategies may reflect a desire to exploit the partner after the break up. Additional research investigating the motivation for each strategy is required. The use of distant / mediated communication in particular is consistent with the emotionally detached interpersonal style displayed by those high on Machiavellianism and research indicating that Machiavellianism influences behaviour online (Abell, \& Brewer, 2014). Though previous research has documented the manner in which digital technologies may both support relationship maintenance (McEwan, 2013; Papp, Danielewicz, \& Cayemberg, 2012) and lead to relationship conflict (Fox, Osborn, \& Warber, 2014) few studies have considered the direct role of these technologies in romantic relationship break ups. Future research should further investigate the use of these technologies and in particular the use of both private (e.g., messaging to instigate a break up) and public (e.g. post negative comments about the relationship or partner) dissolution by those high on Machiavellianism. 
Women high on Machiavellianism experience close social relationships characterised by low levels of emotional security and intimacy (Abell, Brewer, Qualter, \& Austin, 2016). Furthermore, these women report a preference for emotionally distant relationships with low levels of commitment (Ali \& Chamorro-Premuzic, 2010). Hence we predicted that women high on Machiavellianism would experience relatively low levels of post break up distress. Machiavellianism did not however predict break up distress which may reflect the emotional detachment that characterises Machiavellianism. Women with high levels of Machiavellianism receive other more tangible advantages from the romantic relationship. For example, women with high levels of Machiavellianism are more motivated to engage in sexual behaviour for physical reasons and to obtain a goal (Brewer \& Abell, 2015). These women may therefore feel distress at the loss of these advantages rather than the withdrawal of a close personal bond. Further research is required to ascertain women's responses to relationship dissolution and those aspects of the relationship which are most valued.

\subsection{Limitations and Future Research}

The present study was limited by a reliance of self-report retrospective data which may be susceptible to random or inaccurate responding. In particular, participants are likely to over-estimate possession of socially desirable qualities and may be unlikely to report negative behaviours such as the use of manipulation (Pedregon, Farley, Davis, Wood, \& Clark, 2012). Future research should consider the importance of impression management and conceptually related measures such as narcissism, psychopathy, and the HEXACO model. The inclusion of a more diverse sample would also be advantageous. For example, previous research has revealed substantial cross-cultural variation in personality (Allik, 2012) and relationship behaviours (Rodriguez-Arauz, Mealy, Smith \& DiPlacido, 2013). Similarly, adolescents are often less committed to their romantic partner than adults (Rusbult, Martz, \& 
Agnew, 1998) and future studies should investigate the relationship between Machiavellianism and romantic relationship break ups across the lifespan.

The current studies investigated Machiavellianism in relation to the selection of a break up strategy and distress in response to termination of the relationship. We did not however investigate the motivation for the dissolution. Previous research indicates that those with high levels of Machiavellianism are more willing to engage in infidelity (Brewer \& Abell, 2015) and avoid or reduce relationship commitment (Jonason \& Buss, 2012); these are common causes of romantic relationship breakups (Betzig, 1989; Connolly \& McIsaac, 2009). Hence future research should consider the relationship between Machiavellianism and this aspect of relationship dissolution. Furthermore, the present studies did not consider the manner in which partners interact after the break up. For example, women may remain friends with their former partner and may do so for a range of reasons; these include reliability / sentimentality, pragmatism, continued romantic attraction, children, and shared resources, diminished romantic attraction, social relationship maintenance, and sexual access (Mogilski \& Welling, 2016). Subsequent research should therefore address the nature of postbreak up interactions and the perceived benefits of continued contact, particularly as Machiavellianism predicts motivations for sexual behaviour (Brewer \& Abell, 2015).

To conclude, women higher on Machiavellianism were more likely to adopt break up strategies involving manipulation, avoidance / withdrawal, cost-escalation, and distant / mediated communication in order to terminate a relationship. Machiavellianism did not however predict distress in response to relationship dissolution. Further research investigating motivations for the selection of each break up strategy and post break up contact between partners is recommended. 


\subsection{References}

Abell, L., \& Brewer, G. (2016). Machiavellianism, perceived quality of alternative mates, and resistance to mate guarding. Personality and Individual Differences, 101, 236-239.

Abell, L., \& Brewer, G. (2014). Machiavellianism, self-monitoring, self-promotion and relational aggression on Facebook. Computers in Human Behavior, 36, 258-262.

Abell, L., Brewer, G., Qualter, P., \& Austin, E. (2016). Machiavellianism, emotional manipulation, and friendship functions in women's friendships. Personality and Individual Differences, 88, 108-113.

Akert, R.M. (1998). Terminating romantic relationships: The role of personal responsibility and gender. Unpublished manuscript. Wellesley College.

Allik, J. (2012). National differences in personality. Personality and Individual Differences, 53, 114-117.

Ali, F., \& Chamorro-Premuzic, T. (2010). The dark side of love and life satisfaction: Associations with intimate relationships, psychopathy and Machiavellianism. Personality and Individual Differences, 48, 228-233.

Attridge, M., Berscheid, E., \& Simpson, J.A. (1995). Predicting relationship stability from both partners versus one. Journal of Personality and Social Psychology, 69, 254-268.

Banks, S.P., Altendorf, D.M., Greene, J.O., \& Cody, M.J. (1987). An examination of relationship disengagement: Perceptions, breakup strategies, and outcomes. Western Journal of Speech Communication, 51, 19-41.

Baxter, L.A. (1982). Strategies for ending relationships: Two studies. The Western Journal of Speech Communication, 46, 223-241.

Baxter, L.A. (1984). Trajectories of relationship disengagement. Journal of Social \& Personal Relationships, 1, 29-48. 
Baxter, L.A. (1985). Accomplishing relationship disengagement. In S. Duck \& D. Perlman. Understanding Personal Relationships: An Interdisciplinary Approach (pp.243-265). London: Sage.

Betzig, L. (1989). Causes of conjugal dissolution: A cross-cultural study. Current Anthropology, 30, 654-676.

Birkás, B., Láng, A., Martin, L., \& Kálla, J. (2016). Disturbing Concerns for Dark Personalities: Anxiety Sensitivity and the Dark Triad. International Journal of Advances in Psychology, 5, 1-5.

Brewer, G., \& Abell, L. (2015). Machiavellianism and sexual behavior: Motivations, deception and infidelity. Personality and Individual Differences, 74, 186-191.

Christie, R., \& Geis, F.L. (1970). Studies in Machiavellianism. London: Academic Press.

Collins, T.J., \& Gillath, I. (2012). Attachment, breakup strategies, and associated outcomes: The effects of security enhancement on the selection of breakup strategies. Journal of Research in Personality, 46, 210-222.

Connolly, J., \& McIsaac, C. (2009). Adolescents' explanations for romantic dissolutions: A developmental perspective. Journal of Adolescence, 32, 1209-1223.

Davis, D., Shaver, P.R., \& Vernon, M.V. (2003). Physical, emotional and behavioral reactions to breaking up. Personality and Social Psychology Bulletin, 29, 871-884.

Drigotas, S. (1996). Dependence and interaction quality. Paper presented at the Midwest Psychology Association Meetings. Chicago, IL.

Evans, R., Scourfield, J., \& Moore, G. (2014). Gender, relationship breakdown, and suicide risk: A review of research in Western countries. Journal of Family Issues, $0192513 X 14562608$.

Field, T., Diego, M., Pelaez, M., Deeds, O., \& Delgado, J. (2010). Breakup distress and loss of intimacy in university students. Psychology, 1, 173-177. 
Fine, M.A., \& Sacher, J.A. (1997). Predictors of distress following relationship termination among dating couples. Journal of Clinical and Social Psychology, 16, 381-388.

Fisher, H.E. (1989). Evolution of human serial pairbonding. American Journal of Physical Anthropology, 78, 331-354.

Fox, J., Osborn, J.L., \& Warber, K.M. (2014). Relational dialectics and social networking sites: The role of Facebook in romantic relationship escalation, maintenance, conflict, and dissolution. Computers in Human Behavior, 35, 527-534.

Halpern-Meekin, S., Manning, W.D., Giordano, P.C., \& Longmore, M.A. (2012).

Relationship churning in emerging adulthood: On/off relationships and sex with an ex. Journal of Adolescent Research, 0743558412464524.

Helgeson, V.S. (1994). Long-distance romantic relationships: Sex differences in adjustment and breakup. Personality and Social Psychology Bulletin, 20, 254-265.

Hill, C.T., Rubin, Z., \& Peplau, L.A. (1976). Breakups before marriage: The end of 103 affairs. Journal of Social Issues, 32, 147-168.

Ináncsi, T., Láng, A, G., \& Bereczkei, T. (2015). Machiavellianism and adult attachment in general interpersonal and close relationships. Europe's Journal of Psychology, 11, 139-154.

Jonason, P. K., \& Buss, D. M. (2012). Avoiding entangling commitments: Tactics for implementing a short-term mating strategy. Personality and Individual Differences, $52,606-610$.

Jones, D. N., \& Neria, A. L. (2015). The dark triad and dispositional aggression. Personality and Individual Differences, 86, 360-364.

Jones, D. N., \& Paulhus, D. L. (2011a). Differentiating the dark triad within the interpersonal circumplex. In L. M. Horowitz \& S. N. Strack (Eds.), Handbook of interpersonal theory and research (pp. 249-267). New York, NY: Guilford. 
Jones, D.N., \& Paulhus, D.L. (2011b). The role of impulsivity in the Dark Triad of personality. Personality and Individual Differences, 51, 670-682.

Kiecolt-Glaser, J.K., Fisher, L.D., Ogrocki, P., Stout, J.C., Speicher, C.E., \& Glaserm R. (1987). Marital quality, marital disruption, and immune function. Psychosomatic Medicine, 49, 13-34.

Knox, D., Zusman, M.E., \& Nieves, W. (1998). Breaking away: How college students end love relationships. College Student Journal, 32, 482-484.

Kurdek, L.A. (1993). Predicting marital dissolution: A 5-year prospective longitudinal study of newlywed couples. Journal of Personality and Social Psychology, 64, 221-242.

Lambert, A.N., \& Hughes, P.C. (2010). The influence of goodwill, secure attachment, and positively toned disengagement strategy on reports of communication in non-marital post-dissolution relationships. Communication Research Reports, 27, 171-183.

Lampard, R. (2014). Stated reasons for relationship dissolution in Britain: Marriage and cohabitation compared. European Sociological Review, 30, 315-328.

Le, B., Dove, N.L., Agnew, C.R., Korn, M.S., \& Mutso, A.A. (2010). Predicting nonmarital romantic relationship dissolution: A meta-analytic synthesis. Personal Relationships, 17, 377-390.

MacDonald, K. (1995). The establishment and maintenance of socially imposed monogamy in Western Europe. Politics and the Life Sciences, 14, 3-23.

McHoskey, J. (2001). Machiavellianism and sexuality: On the moderating role of biological sex. Personality and Individual Differences, 31, 779-789.

McEwan, B. (2013). Sharing, caring, and surveilling: An actor-partner interdependence model examination of Facebook relational maintenance strategies. Cyberpsychology, Behavior, \& Social Networking, 16, 863-869. 
Mogilski, J.K., \& Welling, L.L.M. (2016). Staying friends with an ex: Sex and dark personality traits predict motivations for post-relationship friendship. Personality and Individual Differences, In Press.

Monroe, S.M., Rohde, P., Seeley, J.R., \& Lewinsohn, P.M. (1999). Life events and depression in adolescence: Relationship loss as a prospective risk factor for first onset of major depressive disorder. Journal of Abnormal Psychology, 108, 606-614.

Olderbak, S.G., \& Figueredo, A.J. (2010). Life history strategy as a longitudinal predictor of relationship satisfaction and dissolution. Personality and Individual Differences, 49, 234-239.

Papp, L.M., Danielewicz, J., \& Cayembeg, C. (2012). “Are we Facebook official?” Implications of dating partners' Facebook use and profiles for intimate relationship satisfaction. Cyberpsychology, Behavior \& Social Networking, 15, 85-90.

Pedregon, C.A., Farley, R.L., Davis, A., Wood, J.M., \& Clark, R.D. (2012). Social desirability, personality questionnaires, and the "better than average" effect. Personality and Individual Differences, 52, 213-217.

Perilloux, C., \& Buss, D.M. (2008). Breaking up romantic relationships. Cost experienced and coping strategies deployed. Evolutionary Psychology, 6, 164-181.

Prigerson, H.G., Maciejewski, P.K., Reynolds, C.F., Bierhals, A.J., Newsom, J.T., \& Fasiczka, A. (1995). The Inventory of Complicated Grief: A scale to measure certain maladaptive symptoms of loss. Psychiatry Research, 59, 65-79.

Robak, R.W., \& Weitzman, S.P. (1998). The nature of grief: Loss of love relationships in young adulthood. Journal of Personal and Interpersonal Loss, 3, 205-216.

Rodriguez-Arauz, G., Mealy, M., Smith, V., \& DiPlacido, J. (2013). Sexual behavior in Costa Rica and the United States. International Journal of Intercultural Relations, 37, 4857. 
Rusbult, C.E., Martz, J.M., \& Agnew, C.R. (1998). The investment model scale: Measuring commitment level, satisfaction level, quality of alternatives and investment size. Personal Relationships, 5, 357-391.

Sbarra, D.A. (2006). Predicting the onset of emotional recovery following nonmarital relationship dissolution: Survival analyses of sadness and anger. Personality and Social Psychology Bulletin, 32, 298-312.

Sherry, S. B., Hewitt, P. L., Besser, A., Flett, G. L., \& Klein, C. (2006). Machiavellianism, trait perfectionism and perfectionist self-presentation. Personality and Individual Differences, 40, 829-839.

Simpson, J.A. (1987). The dissolution of romantic relationships: Factors involved in relationship stability and emotional distress. Journal of Personality and Social Psychology, 53, 683-692.

Sprecher, S. (1994). Two sides to the breakup of dating relationships. Personal Relationships, 1, 199-222.

Sprecher, S., Felmlee, D., Metts, S., Fehr, B., \& Vanni, D. (1998). Factors associated with distress following the breakup of a close relationship. Journal of Social and Personal Relationships, 15, 791-809.

Sprecher, S., Zimmerman, C., \& Abrahams, E.M. (2010). Choosing compassionate strategies to end a relationship: Effects of compassionate love for partner and the reason for the breakup. Social Psychology, 41, 66-75.

Vecchio, R.P., \& Sussman, M. (1991). Choice of influence tactics: Individual and organizational determinants. Journal of Organizational Behavior, 12, 73-80.

Wastell, C., \& Booth, A. (2003). Machiavellianism: An Alexithymic perspective. Journal of Social and Clinical Psychology, 22, 730-744. 
${ }^{1}$ Including relationship length and time since break up did not significantly change the results of the analyses and nor were these significant contributors. 
Table 1: Correlations for Machiavellianism and Break Up Strategy Selection

\begin{tabular}{|c|c|c|c|c|c|c|c|c|}
\hline & MA & AW & PT & $\mathrm{OC}$ & CS & $\mathrm{MN}$ & $\mathrm{DM}$ & $\mathrm{DE}$ \\
\hline MA & & $.20 *$ & -.07 & -.06 & $.32 * *$ & $.25^{*}$ & $.22 *$ & .11 \\
\hline AW & & & .04 & .11 & $.31 *$ & $.33 * *$ & $.33 * *$ & .18 \\
\hline PT & & & & .13 & .09 & .12 & -.06 & $.33 * *$ \\
\hline $\mathrm{OC}$ & & & & & .01 & -.12 & $-.22 *$ & $.20^{*}$ \\
\hline CS & & & & & & $.45^{* *}$ & $.26 * *$ & $.33 * *$ \\
\hline $\mathrm{MN}$ & & & & & & & $.58 * *$ & $.30^{*}$ \\
\hline DM & & & & & & & & .13 \\
\hline $\mathrm{DE}$ & & & & & & & & \\
\hline
\end{tabular}

$* p<.05, * * p<.001$

MA $=$ Machiavellianism, AW $=$ Avoidance $/$ Withdrawal, $\mathrm{PT}=$ Positive Tone $/$ Self-Blame, $\mathrm{OC}=$ Open Confrontation, $\mathrm{CS}=$ Cost Escalation, $\mathrm{MN}=$ Manipulation, $\mathrm{DM}=$ Distant $/$ Mediated Communication, $\mathrm{DE}=\mathrm{De}-$ Escalation 